\title{
Guimarães Rosa e o Regionalismo literário brasileiro: revisão crítica sobre um problema perene
}

\author{
Guimarães Rosa and Brazilian Literary Regionalism: a Critical Review \\ on a Perennial Issue
}

\section{André Tessaro Pelinser}

Universidade de Caxias do Sul - UCS - Caxias do Sul - Brasil

\begin{abstract}
Resumo: Este artigo enfoca a recepção crítica da obra de Guimarães Rosa, a partir de 1946 até o início do século XXI, e analisa os argumentos empregados para lidar com a presença da região na literatura do autor. O discurso crítico, desde o lançamento de Sagarana, manifesta uma relação conturbada com as características comumente associadas ao Regionalismo, ora reconhecendo, ora negando sua presença na ficção rosiana. Ao invés de fomentar novas percepções críticas acerca da literatura produzida com base em espaços regionais, a obra de Guimarães Rosa parece ter contribuído, involuntariamente, para a consolidação de matrizes de pensamento que negam ao regional o estatuto literário. O termo Regionalismo é grafado com inicial maiúscula ao longo do texto, uma vez que ele é aqui tomado como indicador de uma vertente literária.
\end{abstract}

Palavras-chave: Guimarães Rosa; Regionalismo; história da literatura.

Abstract: This essay focuses on the critical reception of Guimarães Rosa's work, from 1946 to the beginning of the 21 st century, and analyzes the arguments employed to deal with the presence of the region in the author's literary work. Since Sagarana's publication, critical discourse has expressed a troubled relationship with the features usually associated with Regionalism, whether by recognizing or denying its presence in Guimarães Rosa's fiction. Instead of encouraging new critical perceptions pertaining literature written in association with regional spaces, Guimarães Rosa's work seems to have contributed, unwillingly, to consolidate building blocks that deny the regional a literary status. Throughout the essay, the term Regionalism is spelled with its first letter capitalized, as it is considered an indicator of a literary strand.

Keywords: Guimarães Rosa; Regionalism; history of literature. 


\section{Introdução}

A apropriada determinação do lugar de Guimarães Rosa na série literária brasileira, a despeito de por vezes parecer questão resolvida, ainda é tema problemático, que toca em pontos sensíveis da tradição crítica nacional. Em vista do processo formativo por que passou a literatura brasileira e das estratégias empregadas para legitimar canonicamente a obra rosiana, criou-se um procedimento de fundo que dá vazão à necessidade de expurgar do texto do autor a marca do Regionalismo. Transformado em espécie de injúria com o passar do tempo, o rótulo ganhou progressivamente tamanho contorno negativo que, segundo apontado com acerto por Marisa Lajolo, em lugar de designar certo tipo de produção literária, foi constantemente requisitado na tradição crítica e na história literária brasileiras "como divisor de águas entre a boa e a má literatura." (2005, p. 327) Guimarães Rosa, situado no polo positivo dessa dualidade, tem sido particularmente afetado por ela, uma vez que a defesa da qualidade de sua obra tem seguidamente coincidido com o apagamento de sua dimensão regional.

No entender de Pierre Bourdieu, tal método não é de todo estranho ao campo das artes, já que boa parte das noções que artistas e críticos empregam para definirem a si mesmos ou a seus adversários "são armas e apostas de lutas, e muitas das categorias que os historiadores da arte aplicam para pensar seu objeto não são mais que esquemas classificatórios oriundos dessas lutas e mais ou menos habilmente mascarados ou transfigurados." (2010, p. 332) Independentemente de serem ou não inicialmente concebidos como insultos ou condenações, os esquemas taxonômicos ganham pouco a pouco um ar de eternidade, graças à amnésia da gênese conferida pelas dissecações críticas e pelas dissertações e teses acadêmicas. ${ }^{1}$

Ainda que a noção de Regionalismo na literatura brasileira não pareça ter sido concebida

\footnotetext{
${ }^{1}$ Bourdieu sustenta que, sim, tais conceitos de combate são na maior parte do tempo concebidos como insultos ou condenações. (Cf. BOURDIEU, 2010, p. 332)
}

como reprovação, é evidente que ao longo da história literária brasileira ela acumulou largo espectro de considerações negativas, as quais se responsabilizaram por the atribuir propriedades depreciativas com ares de eternidade, como se fossem inerentes a toda a vertente, e não particulares a determinadas obras. Como consequência, não é incomum que, ao abordar a produção de Guimarães Rosa como regional ou regionalista, o pesquisador enfrente resistência e por vezes reprovações explícitas de colegas a quem causa surpresa ver tais adjetivos atrelados ao nome canônico do autor. Com efeito, se as obras de arte são primeiramente e acima de tudo objetos estéticos, elas não deixam de estar inseridas em contextos sócio-históricos e submetidas a classificações que não são arbitrárias, tampouco inocentes.

É o que se observa na perspectiva proposta por Jens Stüben, para quem a obra de arte deve ser analisada para além de sua autonomia artística, mas sem ignorar o imperativo estético. Em seus termos, por um lado, "Como ciência histórica, os estudos literários não devem analisar unicamente as estruturas do texto literário e sua potencial representação de um conteúdo supraindividual ou até mesmo atemporal, mas também reconstruir as formas de leitura concretas e os horizontes de compreensão." (STÜBEN, 2013, p. 57) Por outro lado, o mesmo estudioso ressalva que "no centro encontram-se os textos, não as condições sociais e culturais que os produziram e que eles refletem, ou ainda os locais e cenários isolados, aos quais os textos se ligam tematicamente. O exame da materialidade regional deve ser mantido em análises estéticas." (STÜBEN, 2013, p. 58)

O problema que se impõe, no caso do Regionalismo literário brasileiro, é que qualquer tipo de análise parte sempre de um postulado negativo, existente a priori, ao qual deve responder. Desse cenário resultam duas situações de base: a primeira delas refere-se ao juízo crítico acerca das obras consideradas falhas, nas quais os motivos regionais são evocados como explicação para a ineficiência literária; já a segunda delas refere-se ao juízo crítico 
acerca das obras tidas por bem realizadas, nas quais os motivos regionais passam para segundo plano e as razões do êxito literário tendem a ser buscadas em outros elementos. Nesse caso, a estética não deixa de ser o elemento de maior importância no texto literário, mas necessita ser precedida pelo conhecimento da tradição crítica que orienta as "formas de leitura concretas e os horizontes de compreensão", nas expressões de Stüben. De algum modo, a análise estética do Regionalismo precisa sempre se justificar fora da estética.

\section{Um onipresente "mas"}

No que tange ao surgimento de Guimarães Rosa no campo literário brasileiro, tudo leva a crer que a problemática acima referida tenha se imposto de imediato. Antonio Candido, em famoso ensaio de 21 de julho de 1946, publicado em O Jornal, no Rio de Janeiro, devido ao lançamento de Sagarana, identifica o contexto político e ideológico que caracteriza aquele período histórico. Para Candido, "O grande êxito de Sagarana, do Dr. J. Guimarães Rosa, não deixa de se prender às relações do público ledor com o problema do regionalismo e do nacionalismo literário”. (1991b, p. 243) A questão está relacionada aos desenvolvimentos políticos daquela primeira metade do século XX no Brasil, já que trinta anos antes o regionalismo literário se associara em diversas frentes ao federalismo político que se fortalecia, fomentando como reação da inteligentsia local um sentimento de patriotismo como forma de afirmação de unidade nacional. Nesse contexto, os escritores regionais eram procurados como afirmação nativista. Assim, na visão de Candido,

Antes, quando a palavra de ordem política e o sentimento geral eram provincianos, foi chique ser nacionalista, e o porta-voz mais característico da tendência foi Olavo Bilac. Agora, que as forças unitárias predominam e já se vai generalizando um certo sentimento de todo, [...] agora a moda é ser bairrista, e o porta-voz mais autorizado da tendência é o Sr. Gilberto Freyre. (1991b, p. 244)

Nesse meio, Candido considera plenamente compreensível o alvoroço causado pelo surgimento da obra de Guimarães Rosa, compondo um parágrafo em que demonstra incômodo com os excessos partidários ao ironizar a preponderância da região sobre o centro. Em seu entender, Sagarana "vem cheio de 'terra', fazendo arregalar os olhos aos intelectuais que não tiveram a sorte de morar ou nascer no interior (digo, na 'província') ou aos que, tendo nela nascido, nunca souberam do nome da árvore grande do largo da igreja, coisa bem brasileira". (CANDIDO, 1991b, p. 244)

Conquanto a reflexão do autor dê pouco peso à precisão terminológica, o que se compreende devido ao veículo em que foi publicada, e não faça distinções entre bairrismo e regionalismo, ela é capital por registrar o estado do campo das artes e do meio intelectual nacionais quando da inserção de Guimarães Rosa na tradição. Observado em conjunto com as variações nas percepções correntes sobre as diversas formas de localismo, o testemunho do crítico atesta a existência de importantes matizes no imaginário social de então. Tanto a fina ironia a respeito da quantidade de terra que acompanha a obra, quanto a identificação de uma moda bairrista em voga assinalam que Sagarana não é extemporâneo, nem genialmente inexplicável. Na verdade, o livro responde plenamente à estrutura dos possíveis apresentada pelo campo intelectual quando de seu lançamento.

Se seu êxito estético, entrevisto na capacidade de produzir uma fatura estilística que atenda e alargue as convenções do gênero, é evidente mérito do escritor, as disposições para sua leitura seguem os acordos tácitos presentes no campo literário. Do depoimento de Antonio Candido, percebe-se que o Regionalismo não exalava seus últimos suspiros; ${ }^{2}$ pelo contrário, voltava a protagonizar debates intelectuais - não obstante o comentário do autor quanto à "terra" em Sagarana ateste certo incômodo causado por tal constatação. Para além disso, um detalhe pode passar despercebido, mesmo que não seja irrelevante. Desde o início, o escritor-diplomata é

\footnotetext{
2 Ligia Chiappini retoma expressão de José Carlos Garbuglio, para quem "o regionalismo tinha 'fôlego de gato'", ao constatar que a persistência do fenômeno não é exclusividade do Brasil, nem de um momento específico. (CHIAPPINI, 1995, p. 153) Inúmeras vezes dado por encerrado pela crítica literária, as pesquisas de Chiappini mostram que o Regionalismo tem retornado incessantemente sob as mais diversas formas.
} 
tratado segundo a peculiar lógica de distinção social brasileira. Observe-se que não se trata do livro de estreia de João Guimarães Rosa, mas de "Sagarana, do Dr. J. Guimarães Rosa", diplomata que já se fazia conhecido entre a elite intelectual carioca.

Nesse sentido, procedimentos que respondam à sociologia da literatura podem contribuir para a compreensão dos caminhos trilhados pela obra de cada autor e dos pressupostos externos que por vezes são capazes de orientar as apreciações estéticas. De fato, o problema não se restringe ao volume de estreia do autor. Segundo Paulo Moreira, mesmo quando já era considerado por muitos o melhor escritor brasileiro do momento, ainda era palpável a ansiedade que provocava em alguns críticos sua insistência em localizar sua ficção no campo. Por isso, a "solução foi propor que o local em Guimarães Rosa era sumamente superficial, uma capa delgada que ocultava a análise 'das grandes questões humanas'." (MOREIRA, 2012, p. 27)

Essa constante parece ter acompanhado a fortuna crítica rosiana ao longo do tempo. Desde as primeiras impressões sobre Sagarana até as mais recentes reflexões sobre o conjunto da obra, tem sido persistente a evocação de um "mas" que visa a instaurar uma linha divisória clara entre a realidade na qual o texto deita raízes e a dimensão artística dele proveniente. Verifica-se no discurso crítico um palpável desconforto face à necessidade de reconhecer na literatura de Guimarães Rosa a presença do local, da região, do sertão e de populações pobres e analfabetas a quem é negada a capacidade de refletir sobre o mundo, ao mesmo tempo em que busca afirmar a qualidade propriamente literária das narrativas. A recorrente estrutura adversativa de raciocínio culmina com frequência na negação de um dos aspectos mais básicos das obras, a armação sobre a qual se constrói o texto, se movimentam as personagens e se desenham as relações intratextuais que fornecem ao discurso literário suas diversas camadas. 0 procedimento chama a atenção sobretudo quando constatado que não costuma se repetir no repertório crítico destinado aos textos de ambientação urbana, indicando por conseguinte a predominância de um lugar de enunciação e de formas de observação.

No que concerne à ficção rosiana, já em 1946 a problemática posição ocupada pelo Regionalismo e a falta de definição teórica a respeito do tema produzem fricções quando se trata de compreender o lugar da obra na tradição literária. Em outro ensaio inaugural publicado quando do lançamento de Sagarana, desta vez por Álvaro Lins, no Correio da Manhã, do Rio de Janeiro, faz-se patente a oscilação sobre o que vem a ser o Regionalismo e como o texto inovador de Guimarães Rosa com ele se relaciona. A indefinição - que de resto não parece preocupar os críticos - se faz ver na sequência de comentários sobre a presença da região na obra.

Por um lado, os textos "se articulam em bloco como se simbolizassem o panorama de uma região. E Sagarana vem a ser precisamente isto: o retrato físico, psicológico e sociológico de uma região do interior de Minas Gerais", imagem reforçada pela "fidelidade à linguagem popular fixada através dos diálogos". (LINS, 1991, p. 238) Porém, logo em seguida Lins procede a uma ressalva: "Mas o valor dessa obra provém principalmente da circunstância de não ter o seu autor ficado prisioneiro do regionalismo, 0 que 0 teria conduzido ao convencional regionalismo literário, à estreita literatura das reproduções fotográficas, ao elementar caipirismo do pitoresco exterior e do simplesmente descritivo". (1991, p. 239)

Contudo, como a ideia de Regionalismo carece de definição ou sistematização naquele momento, poucas linhas depois surge a contradição:

Em Sagarana temos assim um regionalismo com o processo da estilização, e que se coloca portanto na linha do que, a meu ver deveria ser o ideal da literatura brasileira na feição regionalista: a temática nacional numa expressão universal, o mundo ainda bárbaro e informe do interior valorizado por uma técnica aristocrática de representação estética. (LINS, 1991, p. 239)

Eis que a primeira impressão sobre a obra é a de que ela não se torna prisioneira do Regionalismo e como consequência - tautológica, no interior daquele raciocínio crítico - não se limita ao terreno de um convencional Regionalismo literário, o qual seria 
sinônimo de reprodução fotográfica, elementar caipirismo e descritivismo simplista. Daí decorre um primeiro problema, já que, sendo o Regionalismo literário convencionalmente observado nas letras brasileiras como equivalente à má literatura, a inusitada prosa rosiana parece não poder ser a ele filiada. No entanto, na impossibilidade de negar ao texto certo sabor de terra e de interior, bem como a presença de evidente retrato físico, psicológico e sociológico de uma região de Minas Gerais, advogam-se-lhe as características de um regionalismo com processo de estilização, que seria então capaz de acoplar a temática nacional à expressão universal.

De tal conjunto de pressupostos críticos depreende-se que o restante das obras regionalistas não passariam por processos de estilização, isto é, seriam meras reproduções fotográficas, caipirismo exótico e descrição simples. Porém, gera-se com isso outro problema, porquanto, nessa perspectiva, os demais autores sequer podem ser considerados fotógrafos ou documentaristas, já que parecem incapazes de qualquer estilização. O ponto de partida para todo objeto estético lhes é negado portanto. No caso de Guimarães Rosa, todavia, graças ao processo de estilização, apesar de haver retrato, não há reprodução fotográfica; apesar de haver fidelidade à linguagem popular, não há o simplesmente descritivo.

Condensa-se, portanto, em um pequeno trecho, um conjunto de características díspares e difíceis de conjugar. Conforme o viés por que são abordadas, prestam-se à legitimação ou à condenação de obras e autores. Um dos expedientes mais empregados consiste justamente em fazer vista grossa às semelhanças formadoras de tradições por meio do recurso à noção de universal, como se observou nos excertos apresentados. Muito embora a "técnica aristocrática de representação estética" não seja universal nem absoluta, como provariam nas décadas seguintes as dificuldades para traduzi-la em outros universos linguísticos, ${ }^{3}$ o modo como é

\footnotetext{
${ }^{3}$ Note-se que a correspondência de Guimarães Rosa com seus tradutores teve como subproduto a publicação de dois livros nos
}

defendida produz a crença em sua incondicionalidade, além de sugerir que a tradição regionalista seria incapaz de tal feito e, portanto, de má qualidade.

No mesmo ano de 1946, o outro texto de recepção já mencionado trilha percurso semelhante. No ensaio em que relata suas impressões sobre o primeiro livro de Guimarães Rosa, Antonio Candido destaca:

Mas Sagarana não vale apenas na medida em que nos traz um certo sabor regional, mas na medida em que constrói um certo sabor regional, isto é, em que transcende a região. A província do Sr. Guimarães Rosa, - no caso Minas é menos uma região do Brasil do que uma região da arte, com detalhes e locuções e vocabulário e geografia cosidos de maneira por vezes irreal, tamanha é a concentração com que trabalha 0 autor. [sic] Assim, veremos, numa conversa, os interlocutores gastarem meia dúzia de provérbios e outras tantas parábolas como se alguém falasse no mundo deste jeito. Ou, de outra vez, paisagens tão cheias de plantas, flores e passarinhos cujo nome o autor colecionou, que somos mesmo capazes de pensar que, na região do Sr. Guimarães Rosa, o sistema fito-zoológico obedece ao critério da Arca de Noé. Por isso, sustento, e sustentarei mesmo que provem o meu erro, que Sagarana não é um livro regional como os outros, porque não existe região alguma igual à sua, criada livremente pelo autor com elementos caçados analiticamente e, depois, sintetizados na ecologia belíssima das suas histórias. (CANDIDO, 1991b, p. 244)

Percebe-se, portanto, não apenas uma necessidade de transcendência da obra de arte, que não pode se limitar à região, mas também um imperativo de distanciamento do mundo rural. A título ilustrativo, note-se como não se costuma pensar por esse mesmo viés a obra de um Machado de Assis, por exemplo, cujo microcosmo do Rio de Janeiro não precisa ser transcendido ou ultrapassado. ${ }^{4} \mathrm{O}$ espaço regional rural parece carregar em si a impossibilidade de expressão, de modo que só se obtém êxito fora

quais se registram as dificuldades em verter o texto para os idiomas alemão e italiano.

${ }^{4} \mathrm{Na}$ verdade, nos primórdios da crítica machadiana, costumava ocorrer o oposto. Segundo Roger Bastide, era "a regra, mesmo entre os mais intransigentes admiradores de Machado, reconhecer-lhe na obra essa lacuna, a falta de descrições, a ausência do Brasil tropical”. (BASTIDE, 2002-2003, p. 193) Conforme Antonio Candido (Cf. CANDIDO, 2008), contribuiu para uma mudança de perspectivas justamente o importante estudo do crítico francês, que buscou demonstrar a relevância da urbe carioca e da brasilidade no texto de Machado de Assis, que teria incorporado a paisagem local à filigrana da narrativa, tornando-a elemento funcional da composição literária. 
dele. Nessa mesma linha, enquanto Rio de Janeiro ou São Paulo não deixam de ser cidades (e regiões) do Brasil para transmutarem-se em arte, o sertão mineiro precisa atender a essa premissa, do contrário não passa de local, de paisagem, de reprodução fotográfica, de descrição documental.

Mais interessante é que o crítico identifique o excesso da linguagem e da descrição, mas não reprove a profusão de provérbios e parábolas artificialmente inseridos na fala das personagens, nem o acúmulo descritivo da natureza e dos cenários. Bastou menos do que isso para condenar outros regionalistas. Com efeito, seguidamente tem-se a impressão de que as demais obras se reduzem a retratos fiéis dos espaços regionais, tal qual estudos antropológicos, econômicos e geográficos. Afinal, haveria no mundo algum espaço igual àquele literariamente representado? Não seria, então, toda região construída literariamente com base nos elementos caçados, analisados e sintetizados por seus autores?

De todo modo, por essa transcendência do critério regional que Candido advoga,

o Sr. Guimarães Rosa como que iluminou de repente, [sic] todo o caminho feito pelos antecessores. Sagarana significa, entre outras coisas, a volta triunfal do regionalismo do Centro. Volta o coroamento. De Bernardo Guimarães a ele, passando por Afonso Arinos, Valdomiro Silveira, Monteiro Lobato, Amadeu de Queirós, Hugo de Carvalho Ramos, assistimos a um longo movimento de tomada de consciência, através da exploração do meio humano e geográfico. (1991b, p. 245)

A reflexão do crítico está de acordo, portanto, com o pensamento de Eliot sobre a inserção da obra na tradição, conforme exposto no famoso ensaio "Tradition and the individual talent", pois assinala o momento exato em que são fomentados os rearranjos da série literária. Ao direcionar o facho de luz proveniente de Guimarães Rosa sobre os escritores precedentes, Candido desloca a tradição e propõe, já a partir do primeiro livro de Rosa, o coroamento de um processo. Para além disso, após negar parcialmente o cunho regionalista do volume de novelas - entendido segundo premissas bem pouco claras -, o crítico agora destaca a volta triunfal do Regionalismo precisamente na obra do autor, colocando-o, inclusive, em uma linhagem iniciada por Bernardo Guimarães, a partir da qual se pôde ver um longo movimento de tomada de consciência que parece então chegar a seu auge no texto rosiano.

Esse movimento, na perspectiva de Candido, assistiu à "Fase, precisamente, em que os escritores trouxeram a região até o leitor, conservando, eles próprios, atitude de sujeito e objeto". (CANDIDO, 1991b, p. 245, grifo original) De tal problema, Rosa teria conseguido fugir ao criar uma experiência total. Também para Candido, o desnível imposto pelo distanciamento entre escritor e objeto, entre autor e personagens, apresenta-se como uma das maiores dificuldades a serem vencidas pelo Regionalismo. Se, no entanto, a identificação dessa problemática é correta, talvez não seja tão adequado abordá-la como se os escritores precedentes não tivessem obtido êxitos nesse domínio. Ainda que pequenas e parciais as soluções anteriormente experimentadas tiveram seu quinhão de importância para aproximar os dois universos, de forma que os autores não simplesmente trouxeram a região ao leitor ao longo de toda a tradição literária, até que esta fosse abruptamente salva por Guimarães Rosa. Inclusive porque não se podem ignorar as ressalvas de que Rosa se tornaria objeto tempos depois. É Eduardo Coutinho quem registra

a inadequação, de que Rosa tem sido frequentemente acusado, existente entre 0 nível cultural de seus personagens e a linguagem empregada por eles em seus diálogos e monólogos. Os personagens de Guimarães Rosa são os habitantes do sertão, a maioria gente sem recursos, pertencente às camadas mais baixas da população, que não recebeu nenhuma instrução. No entanto, a linguagem em que se expressam é por vezes bastante elevada e os trechos narrativos e descritivos em que aparecem são relatados de maneira bastante elaborada que não corresponde absolutamente aos padrões de comunicação. (COUTINHO, 1991b, p. 224)

A despeito disso, livrando-se da distância entre sujeito e objeto, segundo a formulação clássica de Candido, "Sagarana nasceu universal pelo alcance e pela coesão da fatura. A língua parece finalmente ter atingido o ideal da expressão literária regionalista. Densa, vigorosa, foi talhada no veio da linguagem popular e disciplinada dentro das tradições clássicas". 
(CANDIDO, 1991b, p. 245) Apesar da elegância da linguagem do crítico e da beleza de sua formulação, o caráter universal da obra não pode lhe ser atribuído como essência, pois está atrelado às circunstâncias de recepção e ao universo cultural em que se insere. Ou seja, é externo à obra e contingente ao grupo social - de maneira que sequer é "universal" de fato. $\mathrm{Na}$ verdade, tal aspecto pode ser entrevisto na própria argumentação de Candido, segundo a qual a linguagem de Sagarana responde a algo esperado dos artistas brasileiros naquele momento: operar a partir da linguagem popular local e ao mesmo tempo conservar fidelidade às tradições clássicas. Neste ponto, é importante que se note: "tradições clássicas" equivale ao conjunto de valores que orientam a percepção do "universal" e que respondem aos pactos valorativos ocidentais baseados em restrita seleção de obras.

Articulações semelhantes continuam a surgir conforme se constitui a fortuna crítica de Guimarães Rosa. Um ano após o lançamento quase simultâneo de Corpo de baile e Grande sertão: veredas, Oswaldino Marques destaca características que começam a se tornar constantes distintivas na obra do autor. Dentre elas, considera autêntica proeza a forma como o artista faz uso de sua "incoercível tendência à monumentalidade" para versar sua temática predileta: "a realidade não menos monumental da vida pastoril brasileira." (MARQUES, 1991, p. 101) Marques salienta ainda a modernidade intrínseca do escritor, mas esse elemento parece conservar alguma incompatibilidade com outro dado importante da obra, seu regionalismo: "Escritor regionalista, que se há revelado até agora [1957], conquanto esta seja apenas uma faceta de sua individualidade, nunca será demasiado ressaltar, num país onde regionalismo é sinônimo de repentismo, a sua incomparável artistry e perfeita sintonia com as conquistas de vanguarda no tocante aos problemas da expressão." (MARQUES, 1991, p. 101)

Isto é, ao mesmo tempo em que a autêntica proeza do artista repousa na realidade monumental da vida pastoril brasileira e na maneira por que ela é estilizada, já nos anos 1950 o fator regional começa a se consolidar como pedra no sapato da produção rosiana. Afinal, o Regionalismo é visto como repentismo e improvisação, de modo que "nunca será demasiado ressaltar" o quanto isso se distancia de sua artistry em perfeita sintonia com as soluções das vanguardas para os problemas da expressão. Tomado por sinônimo de improviso - sob viés negativo -, guarda-se esperança sub-reptícia de que o regionalismo revelado por Guimarães Rosa até aquele momento constitua apenas uma parte de sua literatura, sugerindo-se a possibilidade de caminhos diversos no futuro.

No ano seguinte, Adolfo Casais Monteiro, no prestigiado Suplemento Literário do jornal O Estado de São Paulo, confirma a tendência a identificar o caráter regionalista da prosa rosiana como problemático. Todavia desta vez o crítico vai além e assegura que a "maior injustiça que se pode fazer a Guimarães Rosa é chamar-Ihe autor regionalista, pois que esta designação, a significar alguma coisa, só pode ser que, mimoseando com ela um autor, se pretenda recusar-Ihe a validade universal, fechá-lo nos limites da sua região, como pouco mais que seu memorialista. Não sendo assim, seria o mesmo que chamar regionalista a James Joyce, 'fechado' em Dublin..." (MONTEIRO, 1958, p. 3)

De fato, naquele momento a categoria possui parca definição, como bem registra a reflexão de Monteiro. Contudo, é justamente pelo aparato crítico produzido e fortalecido ao longo da história literária nacional que os contornos do conceito se delineiam. A partir de argumentações como a do referido pesquisador, a noção de Regionalismo progressivamente se equivale à de má literatura, já que, segundo sua perspectiva, não há conciliação possível entre o espaço limitado da região e a validade universal a que supostamente deve fazer jus toda grande obra. De resto, a comparação com a Dublin de Joyce é sintomática sob diversos aspectos, pois, além de vincular o escritor brasileiro a um dos próceres do high modernism, assinala uma confusão conceitual de base. O espaço dublinense entrevisto na obra do autor irlandês não pode receber o epíteto de regional por ser, do ponto de vista do capital 
simbólico e artístico, considerado um espaço central. Isso não impede, entretanto, que sua representação artística seja tomada por localista, sem prejuízo de sua qualidade estética.

O texto rosiano, por sua vez, além de localista, é ambientado em espaço periférico e deserdado, desprovido de herança legítima - muito embora haja toda uma tradição de obras situadas nesse mesmo espaço, ele continua carente de legitimidade artística, de modo que sua presença na grande literatura segue causando incômodo. Não surpreende, portanto, que a crítica de Monteiro recuse exatamente os aspectos localistas da produção de Guimarães Rosa, optando por não ver as "peculiaridades irritantes do estilo" que insistem em registrar "curiosidades localistas" por um preciosismo excessivo na expressão:

Aqueles homens e aquelas paisagens vivem diante de nós, com uma força que não só apaga as curiosidades (extemporâneas para o leitor entusiasta) localistas, como nos faz esquecer certas peculiaridades irritantes do estilo - prova, aliás, de que Guimarães Rosa as podia ter dispensado, e de não serem os excessos de preciosismo na expressão que fazem a beleza da sua prosa; pelo contrário, ela é suficientemente boa para os fazer esquecer e perdoar. (MONTEIRO, 1958, p. 3)

Nessa linha de raciocínio, para apreciar a qualidade das histórias de Guimarães Rosa, o crítico escolhe desconsiderar alguns de seus elementos basilares, ou seja, a profusão descritiva, o detalhismo da expressão, a erudição rebarbativa da palavra, o acúmulo verbal, todos recursos que fornecem densidade e constroem a atmosfera dos textos. O localismo rosiano, esculpido sobre a veia viva do Regionalismo brasileiro, não perde qualidade devido a essas suas características. Na verdade, delas retira sua força para dar ao local o status de arte, sem precisar por isso transcender ou negar o espaço enunciado.

O problema, contudo, persiste. Sob o pseudônimo de Tristão de Ataíde, Alceu Amoroso Lima, em texto intitulado "O transrealismo de G. R." e originalmente publicado em 30 de agosto de 1963 no Jornal do Brasil, do Rio de Janeiro, sustenta que Guimarães Rosa veio para unir na ficção brasileira dois polos que são apenas aparentemente contraditórios: "o espírito telúrico e o espírito oceânico". (ATAÍDE, 1991, p. 142) Chama a atenção, porém, o incômodo causado pela presença do local e do regional na obra do escritor mineiro. Depois de tecer considerações sobre os pontos de contato entre Machado de Assis, Euclides da Cunha e Guimarães Rosa, o crítico assegura: "Mas nada é mais estranho à sua literatura do que o regionalismo". (ATAÍDE, 1991, p. 143, grifo nosso) Nesse ponto, nenhuma novidade; o imprevisto encontra-se na frase seguinte: "Será sertanista mas não regionalista". (ATAÍDE, 1991, p. 143, grifo nosso) Com a ressalva de dois "mas", a literatura rosiana se distancia da pecha do regional, ainda que o próprio Ataíde anteriormente tenha sido forçado a constatar a presença da idiossincrasia de Euclides da Cunha e José de Alencar na ficção do escritor mineiro. A despeito da constatação precedente, o regional não poder ser reabilitado pelo êxito de Guimarães Rosa, já que, por esse viés crítico,

É todo o interior do Brasil, e não apenas os "sertões do Urucuia", por suas paisagens, suas criaturas humanas, seus costumes e sua linguagem, que vive em seus romances e sua [sic] novelas. Nunca limitado a uma região, sendo embora mineiro de nascimento e até de espírito, não é como tal que criou talvez um gênero em nossas letras e forjou seguramente uma linguagem. (ATAÍDE, 1991, p. 143)

Sem explicitar definição consistente que justifique a distinção entre sertanista e regionalista, o crítico paradoxalmente qualifica Guimarães Rosa pelo primeiro termo, já que todo o interior do Brasil, e não apenas os sertões do Urucuia, está representado em suas obras. Isto é, todas as regiões estão aí englobadas, não apenas o sertão, logo o autor é sertanista e não regionalista. Vê-se bem a que ponto chega o problema crítico representado pelo Regionalismo, que passa a exigir da crítica especializada formulações difíceis de serem sustentadas, para tornar possível a separação entre boas e más obras, negando seu pertencimento a uma mesma tradição literária.

Devido a tal necessidade de desvincular Guimarães Rosa do local, ao se referir às traduções, Tristão de Ataíde assegura que "Os estrangeiros, que tiveram contato com essa obra diferente, viram logo o outro aspecto que o seu brasileirismo aparentemente 
esconde: o seu universalismo." (ATAÍDE, 1991, p. 143, grifo original) Tal opinião, entretanto, não é unânime, visto que, segundo Sandra Guardini Vasconcelos, The Devil to pay in the Backlands, versão traduzida de Grande sertão: veredas nos Estados Unidos, "foi lido como um 'Western brasileiro', foi comparado às histórias do oeste em que figuravam Billy the Kid e seu bando, a uma espécie de 'Western, com disputas de revólver e de faca', e tido como 'uma história de aventuras a que falta variedade [...] e um romance de ideias que não consegue ir além do óbvio'”. (VASCONCELOS, 2010, p. 160) Para tanto, certamente contribuíram as falhas de tradução, que enfraqueceram a obra ao optarem por soluções incapazes de atender às particularidades da técnica localista do autor. Segundo se depreende dos comentários do próprio Guimarães Rosa a Curt Meyer-Clason, naquela edição "Tudo virou água, mingau”. (ROSA, 2003a, p. 114)

Não bastasse a dificuldade de defender um universalismo inerente à obra, soma-se o desafio de fazê-lo sem passar pela brasilidade. A despeito disso, em 1964, no clássico ensaio "O homem dos avessos", publicado em Tese e antítese, Antonio Candido, novamente procede à ressalva quanto ao regionalismo do texto rosiano. Este caso é peculiar porque o crítico opta pelo termo "regional", não por "regionalista", o que ilustra o baixo rigor conceitual a que o tema está submetido. No entender de Candido, "tudo se transformou em significado universal graças à invenção, que subtrai o livro à matriz regional para fazê-lo exprimir os grandes lugares-comuns, sem os quais a arte não sobrevive: dor, júbilo, ódio, amor, morte". (1991a, p. 295) Disto se infere que não só as demais obras da tradição regionalista não se interessariam pelos referidos grandes temas motivos arquetipais semelhantes aos estudados por Gilbert Durand em As estruturas antropológicas do imaginário -, como a matriz regional parece incapaz de exprimi-los, sendo necessário subtrair da obra essa dimensão.

Pela consolidação de tais perspectivas críticas, não deve causar estranhamento a opinião expressa por Wilson Martins em estudo divulgado no Suplemento Literário de O Estado de São Paulo, em 8 de maio de 1965, e que faz referência à abordagem de Candido do ano anterior. Conforme Martins, não haveria diferenças caso Grande sertão: veredas fosse ambientado no espaço urbano, até porque o estatuto intelectual de Riobaldo é quase considerado incompatível com sua condição sertaneja. Para o ensaísta,

tudo indica que teremos de voltar ao ponto em que a colocou o sr. Antonio Candido, num ensaio conhecido: Grande sertão é um romance metafísico, que renova, sem dúvida, a "matéria regional", mas no qual o regionalismo é apenas matéria. O romance nada perderia de si mesmo, nem veria modificada a sua essência, se fosse urbano e tivesse por herói um intelectual sofisticado das cidades. (De resto, como concluíram alguns dos meus estudantes num seminário a respeito de Grande sertão, Riobaldo é um intelectual). (MARTINS, 1965, p. 2)

A problemática reside no fato de que, com 0 decorrer das décadas, a dimensão regional da literatura rosiana não deixa apenas de interessar à crítica literária, que enfim assumiria a qualidade artística do texto sem atentar para suas especificidades locais. Pelo contrário, conforma-se uma tradição analítica que precisa recusar o que há de mais básico nas narrativas para só então reconhecer-Ihes os méritos. Chega-se ao limite, como se nota, de avaliar que a obra nada perderia caso fosse completamente diversa, o que bem evidencia o valor da matéria regional.

Até mesmo a recepção a Guimarães Rosa na Academia Brasileira de Letras, em 1967, registra o desconforto causado pela proximidade ao Regionalismo. Proferido por Afonso Arinos de Melo Franco, sobrinho homônimo do autor de Pelo sertão, cuja obra gozava da admiração de Rosa, o discurso de boas-vindas também acaba por enredar-se no espinhoso tema, embora não seja esse seu tópico de interesse: "Escritor ligado à terra, às limitações temporais e espaciais de uma certa terra brasileira, não sois, no entanto, um escritor regional, ou antes, o vosso regionalismo é uma forma de expressão do espírito universal que anima a vossa obra, e, daí, sua repercussão mundial." (FRANCO, 1968, p. 93) Em 
que pesem as negaças iniciais, no caso presente ao menos o Regionalismo não surge como um "mas" a perturbar a suposta expressão universal, senão como uma forma da expressão de tal espírito. Se isso não atenua o problema da crença na universalidade de um texto em tudo particular, pelo menos não transforma em oximoros os termos "região" e "qualidade", "local" e "arte". Mesmo assim, Melo Franco afirma em seguida: "Uma coisa me parece certa, certíssima, e peço licença para anunciá-la frente aos mestres da língua que aqui vejo, um Aurélio Buarque de Holanda, um Augusto Meyer: nada existe de popular em vosso estilo." (FRANCO, 1968, p. 98)

Com efeito, de uma forma ou de outra, o status canônico de Guimarães Rosa precisa ser distanciado da pouca legitimidade do estrato popular, do espaço periférico da região, da percepção de atraso que se opõe à modernidade de sua narrativa. O exame diacrônico das reflexões, porém, demonstra como linhas de pensamento que buscam defender pontos de vista semelhantes se sobrepõem e se contradizem, por causa das dificuldades envolvidas nos processos argumentativos. Precisando lidar com a evidente presença do popular não só nos enredos, como também na catálise do estilo rosiano, as investigações se deparam com um sem número de labirintos.

Já na década de 1980, Eduardo Coutinho reúne em um volume textos representativos da fortuna crítica rosiana até então, os quais não só balizaram a compreensão da obra do autor durante os decênios precedentes, como continuam a constituir importante material de referência ainda hoje. Na "Nota preliminar" à reunião de estudos, assinala-se a tônica que rege o conjunto e consequentemente marca a história da crítica literária. Por um procedimento que reconhece como capa delgada o teor regionalista da ficção rosiana, Coutinho diferencia a obra do escritor mineiro daquela dos regionalistas anteriores pelo destaque dado à paisagem: "Escritor regionalista no sentido de que utiliza como cenário de todas as suas estórias o sertão dos Gerais, e como personagens os habitantes dessa região, o autor transcende os parâmetros do Regionalismo tradicional ao substituir a ênfase até então atribuída à paisagem pela importância dada ao homem - pivô de seu universo ficcional." (COUTINHO, 1991a, p. 14)

Apesar de apontar que Guimarães Rosa difere, inegavelmente, do Regionalismo anterior a ele em diversos aspectos, por mais cuidadosa que seja a posição de Coutinho oferece indícios de um viés de leitura comum a boa parte da historiografia nacional. Por um lado, dá-se por certo que os escritores anteriores ao Modernismo preocupavam-se sobretudo com a paisagem, compreendida a partir da estreita bitola da cor local. Por outro lado, tal viés crítico recorrente costuma tomar a paisagem por algo prejudicial à ficção. Assim procedendo, diminui a importância desse elemento para a fatura final das boas narrativas - o que seria do texto rosiano se despido de seu acúmulo descritivo? -, enquanto lança à sua conta os defeitos das más realizações. Além disso, raramente atenta para o fato de que a paisagem é sempre (ficcionalmente) construída pelo homem e, portanto, fala do homem no tempo e no espaço. Interessar-se pela paisagem não significa esquecer-se do humano, visto que ela é testemunho de sua ação e de seu olhar e participa de sua percepção de mundo.

Mesmo assim, persiste o imperativo de isolar Guimarães Rosa do restante do Regionalismo literário brasileiro devido às técnicas narrativas por ele empregadas. Em 1987, no célebre "Literatura e subdesenvolvimento", estudo constante de $A$ educação pela noite e outros ensaios, Antonio Candido desenha um panorama do pensamento literário brasileiro, traçando relações com a história intelectual latino-americana e tendo como operador conceitual a noção de subdesenvolvimento. No percurso esquematizado pelo crítico, advoga-se uma progressiva tomada de consciência por parte da intelectualidade local acerca da realidade social do Brasil. A reflexão propõe "a distinção de uma terceira fase, que se poderia (pensando em surrealismo, ou super-realismo) chamar de super-regionalista." (CANDIDO, 1989, p. 161, grifo original) Caracterizado 
pela percepção dilacerada do subdesenvolvimento nacional, esse momento aniquilaria a visão naturalista desejosa do conhecimento empírico do mundo e mantenedora do interesse pelo pitoresco e pelo documental. Deste super-regionalismo seria "tributária, no Brasil, a obra revolucionária de Guimarães Rosa, solidamente plantada no que [se] poderia chamar de a universalidade da região." (CANDIDO, 1989, p. 162)

Neste caso, é uma argumentação de fundo socioeconômico que orienta a avaliação crítica das soluções encontradas pelos diferentes autores e das motivações que as geraram. Porém, em lugar de simplesmente revelar como o imaginário de cada época se alterou e fomentou mudanças no aparato estético da tradição literária regionalista, Candido se vê na contingência de segmentá-la para poder situar a produção rosiana em um patamar seguro, no qual porventura fique a salvo da pecha - o próprio autor emprega o termo pouco antes - representada pelas características associadas à vertente. Por conseguinte, Guimarães Rosa acaba por se localizar acima dos demais artistas, como que descolado da série literária, em um processo que pode estimular conclusões perigosas. Se Antonio Candido possui a percuciência para não subtrair o autor à história, o mesmo não parece verificar-se em todos que herdaram tal matriz crítica.

Já no século XXI, imbuído do interesse por historiar a fortuna crítica rosiana, David Jackson procede a um balanço dos estudos sobre o autor até o ano de 2005. Sua análise constata que, sobretudo nas décadas de 1940 e 1950, "Persiste a tendência de ver em JGR uma continuação ou extensão da corrente regionalista, mesmo através das diferenças." (JACKSON, 2006, p. 333) Todavia, não sendo este seu principal objetivo, ao arrolar os argumentos de diversos críticos o estudioso não questiona a maneira como são construídos e como evidenciam o incômodo gerado pela presença da região no texto de Rosa. Se superficialmente parece haver uma consciência da continuidade, a formulação dos argumentos acaba sempre por instaurar uma disjunção entre os elementos. Embora Jackson não entre no mérito da questão, não é outro senão esse o motivo de constatar que, quando do lançamento de Sagarana, "a crítica em geral não tivesse podido especificar exatamente em que consistia essa grandeza literária." (JACKSON, 2006, p. 323) Como se salientou anteriormente, tal incapacidade advém em parte da difícil tarefa de conjugar regional e universal, que marcou os trabalhos sobre a literatura de Guimarães Rosa.

Com efeito, o tema segue relevante no presente século, assinalando a manutenção da necessidade de elevar determinadas obras à esfera do universal. Restrições a elementos estilísticos comumente vinculados ao localismo ou carentes de capital literário são exemplares da imagem consolidada sobre o Regionalismo, conquanto se observe nas últimas décadas um apuro no tratamento da questão. Para Marli Fantini, por exemplo, "Graças ao refinamento técnico de sua linguagem, que inclui, dentre outros, o princípio de aglutinação a colocar em confronto dialógico idiomas distintos, Rosa pôde transfigurar as singularidades regionalistas, levando seus traços anteriormente pitorescos a adquirir universalidade." (FANTINI, 2003, p. 45, grifo nosso) Isto é, Fantini avança em um ponto fundamental ao identificar que os traços pitorescos dos textos rosianos adquirem qualidade sem necessitar recorrer a sua completa negação. Entretanto, não fica claro em que medida, na perspectiva da autora, tais traços deixam de ser pitorescos - conforme sugere 0 emprego do advérbio "anteriormente" - nesse processo. Na verdade, deve-se reconhecer que as narrativas não perdem o sabor regional por atingirem os objetivos da arte - continuam cheias de terra, na expressão de Antonio Candido.

De todo modo, para Fantini, "quando coloca sua região em contato com a esfera transnacional, o escritor amplia os limites de noções estereotipadas como 'regionalismo' ou 'brasilidade' com que se costumou, durante algumas décadas, classificar sua literatura aqui e lá fora." (FANTINI, 2003, p. 75, grifo nosso) Tal postulado é de fato um grande achado, contudo não corresponde ao que se observa no pensamento crítico dominante. A obra de Guimarães 
Rosa deveria ter sido capaz de ampliar a visão estereotipada que se consolidou sobre o Regionalismo, porém essa reabilitação não parece ter se confirmado. Ao invés de ampliar os limites do conceito e de incitar a elaboração crítica de uma tradição, a narrativa rosiana, involuntariamente, incitou ainda mais a desleitura de boa parte dos artistas precedentes, deslocando-os para baixo na bolsa de valores das artes e mantendo os estereótipos acerca do regional.

O próprio Mario Vargas Llosa, em prefácio à edição francesa de Grande sertão: veredas, intitulada Diadorim, aponta peculiaridades a título de defeitos da obra. Procedimento bastante incomum nos dias correntes, é importante recordar que a fala do escritor peruano não deixa de ser a opinião de um concorrente no mercado de capitais das letras. Ainda assim, segundo Llosa, há certa imperfeição no relato de Riobaldo, que não cessa de tergiversar, abrindo parênteses excessivamente longos para refletir sobre questões existenciais e para enunciar postulados esotéricos. (LLOSA, 2006, p. 12) Já do ponto de vista da fatura regionalista, Llosa acredita que Grande sertão: veredas "não está, todavia, isento de certas falhas características do gênero: excesso na descrição, exagero telúrico, abuso de dados geográficos e de informações folclóricas, falta de verossimilhança de certas situações." (LLOSA, 2006, p. 13) Por isso, para o peruano, apenas uma leitura mais atenta e maliciosa salva a obra desses problemas, sendo capaz de perceber as outras camadas nela escondidas. (LLOSA, 2006, p. 13-15)

Conquanto talvez Llosa exagere ao destacar como deficiências certas características do relato riobaldiano, que simula o ritmo fragmentado e incerto da memória, é possível que acerte ao sugerir a malícia e a atenção redobradas imprescindíveis para "salvar" a obra dos "problemáticos" índices regionalistas inegavelmente presentes no texto. Em larga medida, tal afirmação é corroborada por uma análise rigorosa da fortuna crítica rosiana, que em geral busca não só conferir maior relevância a determinadas dimensões em detrimento de outras, como também negar algumas delas.
Francis Utéza se volta para outros aspectos da jornada de Riobaldo, mas em certo sentido confirma a asserção de Llosa. Em sua perspectiva, como livro central no conjunto da produção do escritor mineiro, Grande sertão: veredas traz no frontispício de sua edição brasileira referências geográficas, mas, "para além desse 'regionalismo' de fachada se desenvolve uma busca filosófica de ordem universal concernente a duas grandes tradições espirituais: a tradição hermético-alquímica ocidental e a tradição taoista-zen oriental." (UTÉZA, 2012, p. 49) Enquanto para Vargas Llosa são evidentes as - incômodas - características regionalistas da história de Riobaldo, na perspectiva de Utéza elas parecem se resumir a um "regionalismo" de fachada, que não passa da capa do volume. Além de minimizar a própria armação da narrativa, que se baseia em todo um conjunto de relações cuja verossimilhança depende da regionalidade que professam, o imperativo de reduzir o regional a uma fina camada do texto desconsidera o papel de Guimarães Rosa na escolha do projeto gráfico original de Grande sertão: veredas, que instaura uma separação existencial com base nas duas margens do rio São Francisco.

Enfim, a permanência de matrizes críticas às quais o espaço periférico e inculto dos interiores do Brasil se afigura incompatível com questões que não sejam rasas tem dado a tônica das incursões sobre o tema. Não é incomum, nesse sentido, que, em vista da pressuposta inconciliável distância entre Guimarães Rosa e o restante da literatura brasileira, o autor seja extraído da história e situado no domínio do inexplicável, como demonstra este estudo datado de 2009:

Já no decênio de 1940, período em que Rosa surge definitivamente para a literatura, esta não mais possuía o fôlego para produzir escritores que soubessem apropriar-se do mesmo expediente utilizado pelo autor de Tutaméia, isto é, a ruptura com os limites impostos pelo naturalismo e o pitoresco, cujo resultado - como se pode perceber em Simões Lopes Neto, ou mesmo em Mário Palmério - foi a imersão de nossas letras no terreno perigoso de dependência estética em relação à recepção simpática dos leitores europeus, ávidos por obras que mostrassem uma terra, um homem e um espaço exóticos, inscritos todos numa batalha socioeconômica violenta pela sobrevivência, ou seja, uma 
ambiência não encontrada facilmente nas literaturas dos países desenvolvidos do Velho Mundo. (TEIXEIRA et al., 2009, p. 160)

Ancorado em uma série de premissas consolidadas por anos de crítica acerca da suposta subserviência histórica da literatura brasileira em relação a modelos europeus, o trabalho guarda outro ponto de interesse a respeito de Guimarães Rosa. Se o diplomata mineiro é claramente tomado por salvador das letras nacionais ao encontrar o caminho para uma expressão individual face à imposição de normas caducas, por outro lado ele também se apresenta descolado do campo artístico de seu tempo. Afinal, se a literatura de então já não possuía fôlego para produzir escritores capazes de adotar novos expedientes estilísticos e possivelmente romper com o Naturalismo e o pitoresco, como compreender o aparecimento de Guimarães Rosa?

O caráter divinizante que se observa com certa frequência na crítica à obra de Guimarães Rosa concorre para uma percepção a-histórica de sua gênese, pela qual é prejudicada a compreensão das tradições literárias e das relações sincrônicas e diacrônicas entre obras e autores. Em certo sentido, entrelaçam-se, de um lado, a negação de determinados pontos de contato de Guimarães Rosa com a história literária brasileira e, de outro, a recusa da presença legítima de um espaço e suas características na ficção rosiana:

O toque de Midas rosiano estabelece no temário regional uma nova concepção do espaço sertanejo, agora distante do caráter exótico, mágico ou ainda da sua representação documental, o Sertão não aparece mais limitado às fronteiras geográficas do Nordeste brasileiro, mas estende-se às incursões nos conflitos e dramas universais, em outras palavras, o Sertão não é mais Sertão, é - como revela Riobaldo Tatarana - o mundo. (TEIXEIRA et al., 2009, p. 161)

Com efeito, se Riobaldo afirma categoricamente que o sertão é o mundo, seu discurso em nenhum momento nega o próprio sertão ou sugere que para ser metáfora existencial esse espaço precise abandonar a si mesmo. O sertão é o mundo por ser tão propenso quanto qualquer outro espaço a encenar os dramas humanos. O sertão não deveria operar sob um signo de negação; o sertão é pura e simplesmente o mundo. Naquele espaço, assim como fora dele, as fronteiras são tênues, as certezas são fracas, tudo é muito misturado e a experiência humana é breve e frágil. Se o sertão é onde os pastos carecem de fecho, ele não deixa de ser cortado por um rio que assinala o limiar entre os judas e os riobaldos, ainda que a maldade possa estar presente em ambos os lados.

Como se observa em artigo de Leonel e Segatto, até mesmo Antonio Candido em certo momento flertou com uma perspectiva deshistoricizante. Em avaliação publicada no Suplemento Literário de $O$ Estado de São Paulo sob o título "Grande sertão: veredas", quando do lançamento do livro, e republicada em Textos de intervenção com o título "No grande sertão", o crítico afirmaria que aquela narrativa "Não segue modelos, não tem precedentes; nem mesmo, talvez, nos livros anteriores do autor, que, embora de alta qualidade, não apresentam a sua característica fundamental: transcendência do regional (cuja riqueza peculiar se mantém todavia intacta)". (CANDIDO apud LEONEL; SEGATTO, 2009, p. 120) Conforme Leonel e Segatto, para enfatizar esse ponto, "o crítico praticamente desdiz o que havia escrito sobre Sagarana em resenha que salienta o universalismo dos contos publicados em 1946." (LEONEL; SEGATTO, 2009, p. 120)

Vê-se bem o emaranhado que se cria para defender a transcendência do regional rumo ao universal, pois o mesmo Antonio Candido que aclamara as qualidades surpreendentes de Sagarana e traçara uma linhagem a partir de Bernardo Guimarães, conforme apontado anteriormente, agora não só descola Guimarães Rosa da tradição literária nacional, como também das constantes presentes no conjunto de sua obra. Não obstante, a partir da análise dos postulados de Candido, Leonel e Segatto concordam que "a obra rosiana, principalmente Grande sertão: veredas, supera a tradição literária do regionalismo, muitas vezes marcada pelo naturalismo ou pela caricatura, que é baseada na observação (empírica e documental) e que resulta na descrição de personagens, atos e espaços que, como cópia 
fotográfica, parecem estáticos e até mesmo, natureza morta." (LEONEL; SEGATTO, 2009, p. 121)

Segundo tal panorama, o texto rosiano não pode se inscrever na tradição do Regionalismo brasileiro, deve antes ultrapassá-la. Afinal, a obra é apreendida como completamente diversa de uma vertente que não teria sido capaz de ir além da cópia fotográfica e da natureza morta, embora também a ficção rosiana se baseie na observação empírica e documental e proceda a densas descrições. Talvez a história literária brasileira pudesse tirar maior proveito de suas realizações caso admitisse as verdadeiras raízes dessa ficção e empregasse os resultados por ela fornecidos para capitalizar seus produtos. De resto, é interessante que o pesquisador italiano Roberto Mulinacci fale "numa das mais emblemáticas paisagens da literatura mundial: 0 sertão" (MULINACCI, 2009, p. 12), enquanto a crítica literária brasileira não cessa de tomá-lo por incômodo. A não ser que se considere Guimarães Rosa o detentor exclusivo da capacidade de conferir a esse espaço relevância mundial, deve-se conceder que sua gênese se deu no bojo de uma tradição e é tributária de autores como Franklin Távora, José de Alencar, Coelho Neto, Afonso Arinos, Euclides da Cunha, Bernardo Guimarães, Hugo de Carvalho Ramos, Mário Palmério e tantos outros.

O próprio Guimarães Rosa, em contrapartida ao dito "sentido metafísico" de suas narrativas, ressalta a presença massiva do sertão, fazendo até mesmo uma ressalva quanto a seu possível excesso. Em correspondência ao tradutor italiano Edoardo Bizzarri, o escritor procura elucidar detalhes de Corpo de baile, assegurando que "o sertão é de suma autenticidade, total. Quando eu escrevi o livro, eu vinha de lá, dominado pela vida e paisagem sertanejas. Por isto mesmo, acho, hoje, que há nele certo exagero na massa da documentação." (ROSA, 2003b, p. 90) Com isso, torna-se custoso negar o caráter documental e descritivo da obra do autor, carregada de elementos pitorescos e de passagens de inspiração naturalista, o que, entretanto, não impede a boa fatura dos textos, já que esses elementos não carregam em si nenhuma incompatibilidade com a síntese artística.

Operando em chave levemente diversa, Walnice Nogueira Galvão, em trabalho intitulado "Sobre o Regionalismo", investiga a pertinência da vinculação de Guimarães Rosa à tradição regionalista, procurando aliar duas visões conflitantes. Um primeiro aspecto que chama a atenção é o emprego da inicial maiúscula para se referir à vertente, conferindo-Ihe status de tradição literária, para além de simples agrupamento de características. Já na primeira frase revelam-se os caminhos que a estudiosa pretende tomar: "Pode-se especular se a obra de Guimarães Rosa não assinalaria ao mesmo tempo o apogeu e o encerramento do Regionalismo." (GALVÃO, 2008, p. 90) Segundo Galvão, o autor teria explorado até o limite as possibilidades da vertente, inesperadamente fecundando-a com as inovações formais das vanguardas do século $X X$, de modo que teria podido ultrapassar 0 particularismo e 0 neonaturalismo do romance de 30 , mas sem prejuízo dos méritos alcançados pelo período. (GALVÃO, 2008, p. 91)

Embora talvez demasiadamente absorta no problema da superação, Galvão fornece caminhos interessantes ao optar igualmente por um pensamento de síntese. Para a autora:

Guimarães Rosa vai representar uma síntese feliz e uma superação das duas vertentes [0 Regionalismo e o romance espiritualista ou psicológico]. Como os regionalistas, volta-se para os interiores do país, pondo em cena personagens plebeus e "típicos" a exemplo dos jagunços sertanejos, levando a sério a função da literatura como documento até ao ponto de reproduzir a linguagem característica, se bem que devidamente recriada ou reelaborada, daquelas paragens. Mas, como os personagens do romance espiritualista ou psicológico, manejando largo sopro metafísico, costeando o sobrenatural, preocupado talvez menos com o pecado, porém sem dúvida mais com a graça, em demanda da transcendência. (GALVÃO, 2008, p. 91-92, grifo nosso)

Deixando de lado pressuposições negativas sobre a descrição regionalista, a pesquisadora se afasta da concepção rasteira do Regionalismo como "documentário, logo de má qualidade." Galvão reconhece o teor regionalista dos textos e procura 
demonstrar como essa faceta não exclui ou impossibilita as demais dimensões da narrativa, e o faz sem operar sob um declarado signo de negação. Ainda assim, pode-se questionar em que medida se trata de superação de vertentes, uma vez que o Regionalismo segue presente na ficção brasileira. Mais do que superar, possivelmente seja o caso de esgarçar, modificar, adicionar novas possibilidades às vertentes literárias, que absorvem novos recursos e se transmutam. Nesse sentido, é possível que a ideia de síntese constitua achado mais produtivo para avaliar os efeitos das grandes obras no cerne das tradições artísticas.

\section{Considerações finais}

Sem dúvida, parte da problemática que envolve o Regionalismo e sua capacidade de representar artisticamente o mundo se reporta ao conflito entre história e literatura abordado por Pascale Casanova ao final de $A$ república mundial das letras. Marcado pela temporalidade própria que caracteriza a literatura como campo artístico autônomo, tal embate diz respeito a uma visão segundo a qual a literatura, como ato artístico, seria irredutível à história. Nos termos de Casanova, "o autor como exceção e o texto como inatingível infinito foram declarados consubstanciais à definição mesma do gesto literário, e engendraram uma exclusão, uma expulsão, ou, para falar a linguagem do sagrado literário, uma excomunhão da história, acusada de incapaz de se elevar alto o bastante no céu das formas puras da arte literária." (CASANOVA, 2008, p. 484) Para uma parcela dos teóricos da literatura, compreendidas como pertencentes a uma "outra temporalidade", irredutível à cronologia ordinária, as formas literárias não mudariam segundo o ritmo do mundo. Sendo assim, as obras não poderiam ser compreendidas no tempo histórico, mas apenas em sua singularidade própria, de modo que nunca estão plenamente na história - estão sempre a superá-la.

A autora, no entanto, problematiza a fundo essa questão ao longo de todo o livro, no qual busca demonstrar o entrelaçamento dos dois domínios, singularidade artística e condição histórica. Para Casanova, tal proposta é viável ao se fazer da literatura um objeto temporal sem reduzi-la à série de acontecimentos do mundo, mas a inserindo no tempo histórico e mostrando como aos poucos, por um lento processo de autonomização, ela escapa às leis históricas habituais. Com isso, a literatura poderia ser definida, a um só tempo e sem contradições, como objeto irredutível à história e como objeto histórico, cuja historicidade seria estritamente literária. (CASANOVA, 2008, p. 485-486) Nessa linha, o escritor seria situado duas vezes no espaço-tempo literário: por um lado, segundo a posição do espaço literário nacional do qual ele provém; por outro, segundo o lugar que ele ocupa nesse espaço nacional. (CASANOVA, 2008, p. 486-487)

Daí o perigo de uma crítica "pura", caracterizada pela projeção de suas próprias categorias estéticas sobre os textos, o que, para a estudiosa francesa, possui como consequência frequente a inobservância das particularidades próprias ao espaço nacional e político de cada literatura. (CASANOVA, 2008, p. 488) Evidentemente, a reflexão de Casanova busca dar conta dos espaços centrais na "república mundial das letras", analisando seu poder de legislar etnocentricamente, e é imprescindível reconhecer o constante alinhamento da crítica brasileira às regras provenientes de tais capitais da cultura. Como resultado, não raramente ignoram-se os imperativos históricos e políticos aos quais se submetem os escritores para entrarem no mapa literário, professa-se a separação dos grandes gênios de seus pares menos cotados e fomenta-se a obliteração de sua dimensão particular pela superação das tradições locais.

Para Pascale Casanova, a história literária de Kafka é exemplar não só do etnocentrismo de tais procedimentos, como também do anacronismo que seguidamente assumem. Em seu entender, sendo a consagração literária do autor inteiramente póstuma, há um anacronismo fundamental que separa o espaço literário (e político e intelectual) no qual o escritor pôde produzir e o espaço literário (e político e intelectual) de recepção de sua obra. Entrando no 
universo literário que o consagra após 1945 como um dos fundadores da modernidade, Kafka perde de um só golpe todas suas características nacionais e culturais, ocultadas pelo processo de universalização.

(CASANOVA, 2008, p. 488-489)

Ainda que no caso brasileiro não se observem tão flagrantes anacronismos, em certa medida 0 mesmo processo etnocêntrico - mas aplicado pela própria crítica nacional imbuída dos pactos valorativos canônicos - opera uma desparticularização similar quando se trata da consagração de Guimarães Rosa. É o que se constata quando os caracteres específicos na obra do autor, vinculados às tradições literárias brasileiras e sobretudo ao Regionalismo, são tomados por praticamente irrelevantes frente a um suposto reconhecimento universal, ao qual se atribui valor tão elevado que a importância nacional da obra se apequena: "E no sucesso das traduções, despojadas e desornadas de todas as joias e rendas da fala nativa, se vê que o escritor é um artista que realizou o lugar-comum de atingir o universal, pelo regional." (PROENÇA, 1974, p. 457)

De fato, mais importante do que superar os feitos dos artistas precedentes ou suprimir a dimensão local das obras em prol da crença em um universal, encontra-se o imperativo de reconhecer a literatura em sua tradição histórica. Atrelada a uma historicidade externa, de cunho social, intelectual, político e econômico, e detentora de uma historicidade interna, própria ao campo enquanto instância autônoma, a literatura é situada no tempo e no espaço. Pelas relações construídas nessa estrutura de possíveis, conforma-se uma percepção de conjunto que não deve ser descartada.

Como se demonstrou com base na obra de Guimarães Rosa, face ao onipresente "mas" por meio do qual são difundidas as recorrentes denegações de estatuto literário aos caracteres regionalistas - e, por vezes, ao próprio Regionalismo - merecem destaque algumas consequências desse processo no âmbito da história literária. Por um lado, vê-se embaçada a gênese artística da produção rosiana, já que as obras não podem ser apropriadamente situadas em relação à tradição literária à qual pertencem. Por outro, embora essa constante ressalva não resista a um exame detalhado, sua permanência tem se mostrado um eficiente mecanismo de perpetuação da divisão entre boa e má literatura com base na ideia de Regionalismo, rótulo este que deveria designar unicamente uma vertente literária.

Pode-se conjeturar, portanto, que o surgimento de Guimarães Rosa na literatura brasileira tenha sido assimilado pela tradição crítica como momento crucial para o fortalecimento de visões que se gestavam há décadas. Ao invés de ressignificarem positivamente a tradição precedente e atarem pontas entre as diferentes soluções experimentadas ao longo de cerca de um século de literatura, os deslocamentos que o texto rosiano engendrou foram incorporados de modo a corroborar as limitações que a crítica considerava próprias ao gênero regionalista. Com isso, o emprego do "mas" restritivo, visando à elevação do texto rosiano ao patamar da grande literatura, tem conseguido manter subavaliada a tradição regionalista e tem causado uma série de empecilhos a um raciocínio crítico que tome por foco os aspectos estéticos do Regionalismo sem que este seja associado à ideia de má literatura. Encontrandose na contingência de reconhecer a regionalidade da obra do autor ao mesmo tempo em que precisa assegurar sua qualidade artística, a crítica literária não tem mostrado predisposição a avançar na discussão e revelar como os dois elementos não são incompatíveis.

Afinal, do precursor registro da poesia da gesta do gado feito por Alencar para escrever $O$ sertanejo, passando pela narrativa de Távora entremeada de trovas populares e pelo programa de estudo da linguagem e do folclore gaúchos de Apolinário PortoAlegre (Cf. CHIAPPINI, 1994, p. 675-676), constituiuse um rico caldeirão de referências, sempre reaproveitado e retrabalhado, em constante mutação, que forneceu à literatura brasileira um espaço simbólico seminal, cuja imagem em momento nenhum aponta para a pequenez artística que a historiografia muitas vezes fez crer. Nos termos de Ligia Chiappini, para se chegar ao requinte com que Guimarães Rosa ressignificou o repositório da 
tradição, "foi necessário trilhar um longo caminho para criar e fortalecer uma vertente riquíssima da literatura brasileira que tem seus equivalentes nas obras da literatura hispano-americana, daqueles que Ángel Rama chama de transculturadores." (CHIAPPINI, 1994, p. 676)

\section{Referências}

ATAÍDE, Tristão de. O transrealismo de G. R. In: COUTINHO, Eduardo (Org.). Guimarães Rosa (Coleção Fortuna Crítica). 2. ed. Rio de Janeiro: Civilização Brasileira, 1991. p. 142-143.

BASTIDE, Roger. Machado de Assis, paisagista. REVISTA USP, São Paulo, n. 56, p. 192-202, dez./fev. $2002-2003$.

BOURDIEU, Pierre. As regras da arte: gênese e estrutura do campo literário. Trad.: Maria Lucia Machado. 2. ed. São Paulo: Companhia das Letras, 2010.

CANDIDO, Antonio. Esquema de Machado de Assis. In: ASSIS, Machado de. Obra completa, em quatro volumes: volume 1. 2. ed. Rio de Janeiro: Nova Aguilar, 2008. p. 112-124.

CANDIDO, Antonio. Literatura e subdesenvolvimento. In: A educação pela noite e outros ensaios. 2. ed. São Paulo: Ática, 1989. p. 140-162.

CANDIDO, Antonio. O homem dos avessos. In: COUTINHO, Eduardo (Org.). Guimarães Rosa (Coleção Fortuna Crítica). 2. ed. Rio de Janeiro: Civilização Brasileira, 1991a. p. 294-309.

CANDIDO, Antonio. Sagarana. In: COUTINHO, Eduardo (Org.). Guimarães Rosa (Coleção Fortuna Crítica). 2. ed. Rio de Janeiro: Civilização Brasileira, 1991b. p. 243-247.

CASANOVA, Pascale. La république mondiale des lettres. Edição revista e corrigida. Paris: Éditions du Seuil, 2008.

CHIAPPINI, Ligia. Do beco ao belo: dez teses sobre o regionalismo na literatura. Estudos Históricos, Rio de Janeiro, vol. 8, n. 15, p. 153-159, 1995. Disponível em: $<$ http://virtualbib.fgv.br/ojs/index.php/reh/article/vie w/1989/1128>. Acesso em: 03 jun. 2010.

CHIAPPINI, Ligia. Velha praga? Regionalismo literário brasileiro. In: PIZARRO, Ana (Org.). América Latina: palavra, literatura e cultura. Vol. 2. São Paulo: Memorial; Campinas: UNICAMP, 1994. p. 665-702.

COUTINHO, Eduardo. Nota preliminar. In: COUTINHO, Eduardo (Org.). Guimarães Rosa (Coleção Fortuna Crítica). 2. ed. Rio de Janeiro: Civilização Brasileira, 1991a. p. 13-15.
COUTINHO, Eduardo. Guimarães Rosa e o processo de revitalização da linguagem. In: COUTINHO, Eduardo (Org.). Guimarães Rosa (Coleção Fortuna Crítica). 2. ed. Rio de Janeiro: Civilização Brasileira, 1991b. p. 202-234.

DURAND, Gilbert. As estruturas antropológicas do imaginário. Trad.: Hélder Godinho. 3.ed. São Paulo: Martins Fontes, 2002.

ELIOT, Thomas Stearns. Tradition and the individual talent. In: The Sacred Wood: essays on poetry and criticism. 7. ed. Londres: Methuen \& Co. Ltd., 1950.

FANTINI, Marli. Guimarães Rosa: fronteiras, margens, passagens. Cotia, SP: Ateliê Editorial; São Paulo: Editora SENAC São Paulo, 2003.

FRANCO, Afonso Arinos de Melo. O verbo \& o logos - discurso de recepção de Afonso Arinos de Melo Franco. In: ANDRADE, Carlos Drummond de; PEREZ, Renard; RAMOS, Graciliano et al. Em memória de João Guimarães Rosa. Rio de Janeiro: Livraria José Olympio Editora, 1968. p. 89-106.

GALVÃO, Walnice Nogueira. Mínima mímica: ensaios sobre Guimarães Rosa. São Paulo: Companhia das Letras, 2008.

JACKSON, K. David. Certo sertão: sessenta anos de fortuna crítica de Guimarães Rosa. O eixo e a roda, Belo Horizonte, v. 12, p. 323-342, 2006. Disponível em: $<$ http://www.letras.ufmg.br/poslit/08_publicacoes_t xt/er 12/er12 dj.pdf>. Acesso em: 31 out. 2012.

LAJOLO, Marisa. Regionalismo e história da literatura: quem é o vilão da história? In: FREITAS, Marcos Cezar (Org.). Historiografia brasileira em perspectiva. 6. ed. São Paulo: Contexto, 2005. p. 297-328.

LEONEL, Maria Célia; SEGATTO, José Antonio. O sertão-mundo de Guimarães Rosa. Légua \& meia: revista de literatura e diversidade cultural. Feira de Santana, UEFS, v. 7, n. 5, 2009, p. 114-123. Disponível em: <http://leguaemeia.uefs.br/5/5_11sertao.pdf> Acesso em: 3 nov. 2014.

LINS, Álvaro. Uma grande estreia. In: COUTINHO, Eduardo (Org.). Guimarães Rosa (Coleção Fortuna Crítica). 2. ed. Rio de Janeiro: Civilização Brasileira, 1991. p. 237-242.

LLOSA, Mario Vargas. Épopée du sertão, tour de Babel ou manuel de satanisme? [Prefácio] In: ROSA, João Guimarães. Diadorim. Paris: Éditions Albin Michel, 2006. p. 11-15.

MARQUES, Oswaldino. O repertório verbal. In: COUTINHO, Eduardo (Org.). Guimarães Rosa (Coleção Fortuna Crítica). 2. ed. Rio de Janeiro: Civilização Brasileira, 1991. p. 101-112. 
MARTINS, Wilson. Jõe Guimarró. O Estado de São Paulo, São Paulo, 8 mai. 1965. Suplemento Literário, p. 2.

MONTEIRO, Adolfo Casais. Guimarães Rosa não é escritor regionalista. O Estado de São Paulo, São Paulo, 8 mar. 1958. Suplemento Literário, p. 3.

MOREIRA, Paulo. Modernismo localista das Américas: os contos de Faulkner, Guimarães Rosa e Rulfo. Belo Horizonte: Editora UFMG, 2012.

MULINACCI, Roberto. Um deserto cheio de lugares: topografias literárias do sertão. In: RAVETTI, Graciela; CURY, Maria Zilda; ÁVILA, Myriam (Orgs.). Topografias da cultura: representação, espaço e memória. Belo Horizonte: Editora UFMG, 2009. p. 11-31.

PROENÇA, Manoel Cavalcanti. Estudos literários. 2. ed. Rio de Janeiro: José Olympio; Brasília: INL, 1974.

ROSA, João Guimarães. João Guimarães Rosa: correspondência com seu tradutor alemão Curt Meyer-Clason (1958-1967). Ed. org. e notas Maria Apparecida Faria Marcondes Bussolotti; trad. Erlon José Paschoal. Rio de Janeiro: Nova Fronteira : Academia Brasileira de Letras; Belo Horizonte: Editora UFMG, 2003a.
ROSA, João Guimarães. João Guimarães Rosa: correspondência com seu tradutor italiano Edoardo Bizzarri. 3. ed. Rio de Janeiro: Nova Fronteira; Belo Horizonte: Editora UFMG, 2003b.

STÜBEN, Jens. Literatura regional e literatura na região. In: ARENDT, João Claudio; NEUMANN, Gerson Roberto (Orgs.). Regionalismus Regionalismos: subsídios para um novo debate. Caxias do Sul: Educs, 2013. p. 37-73.

TEIXEIRA, Everton Luís Faria; HOLANDA, Silvio Augusto de Oliveira; ARAÚJO, Elissandro Lopes de. Antonio Candido e o supra-regionalismo rosiano ou o social e o literário como fios de um tecido inextrincável. Revista Cerrados, v. 18, n. 28, p. 157-181, 2009. Disponível em: <http://seer.bce.unb.br/index.php/cerrados/article/v iew/8320/6316>. Acesso em: 2 ago. 2011.

UTÉZA, Francis. Du Guaicuí au Verde-Alecrim: la langue des oiseaux. In: OLIVIERI-GODET, Rita; WREGE-RASSIER, Luciana (Orgs.). João Guimarães Rosa: mémoire et imaginaire $d u$ sertão-monde. Rennes: Presses Universitaires de Rennes, 2012. p. 49-76.

VASCONCELOS, Sandra Guardini. João \& Harriet: notas sobre um diálogo intercultural. In: FANTINI, Marli. Machado e Rosa: leituras críticas. Cotia, SP: Ateliê Editorial, 2010. p. 153-161.

\section{COMO CITAR ESSE ARTIGO}

PELINSER, André Tessaro. Guimarães Rosa e o Regionalismo literário brasileiro: revisão crítica sobre um problema perene. Signo, Santa Cruz do Sul, v. 42, n. 74, maio 2017. ISSN 1982-2014. Disponível em: $<$ https://online.unisc.br/seer/index.php/signo/article/view/8605>. Acesso em: http://dx.doi.org/10.17058/signo.v42i74.8605. 